\title{
ERRATUM
}

\section{Erratum to: Evaluation of a New Formulation of Epoprostenol Sodium in Japanese Patients with a Pulmonary Arterial Hypertension (EPITOME4)}

Yuichi Tamura $\cdot$ Tomohiko Ono $\cdot$ Keiichi Fukuda

Toru Satoh $\cdot$ Shigetake Sasayama

To view enhanced content go to www.advancesintherapy.com

Received: May 9, 2013 / Published online: May 25, 2013

(C) Springer Healthcare 2013

ERRATUM TO: Adv Ther

DOI 10.1007/s12325-013-0029-0

The authors of the above mentioned paper would like to make the following adjustment to their article. In Table 4, the column heading titled "After $60 \mathrm{~min} \quad(n=8)$ " should read "12 weeks of administration $(n=8)$ ". The corrected table is published here:

The online version of the original article can be found under doi:10.1007/s12325-013-0029-0.

Y. Tamura $(\bowtie) \cdot$ T. Ono $\cdot$ K. Fukuda

Department of Cardiology, Keio University School

of Medicine, 35 Shinanomachi Shinjuku-ku,

Tokyo, Japan

e-mail: u1@ta-mu.net

T. Satoh

Department of Cardiology, Kyorin University

School of Medicine, Tokyo, Japan

S. Sasayama

Kyoto University, Kyoto, Japan 


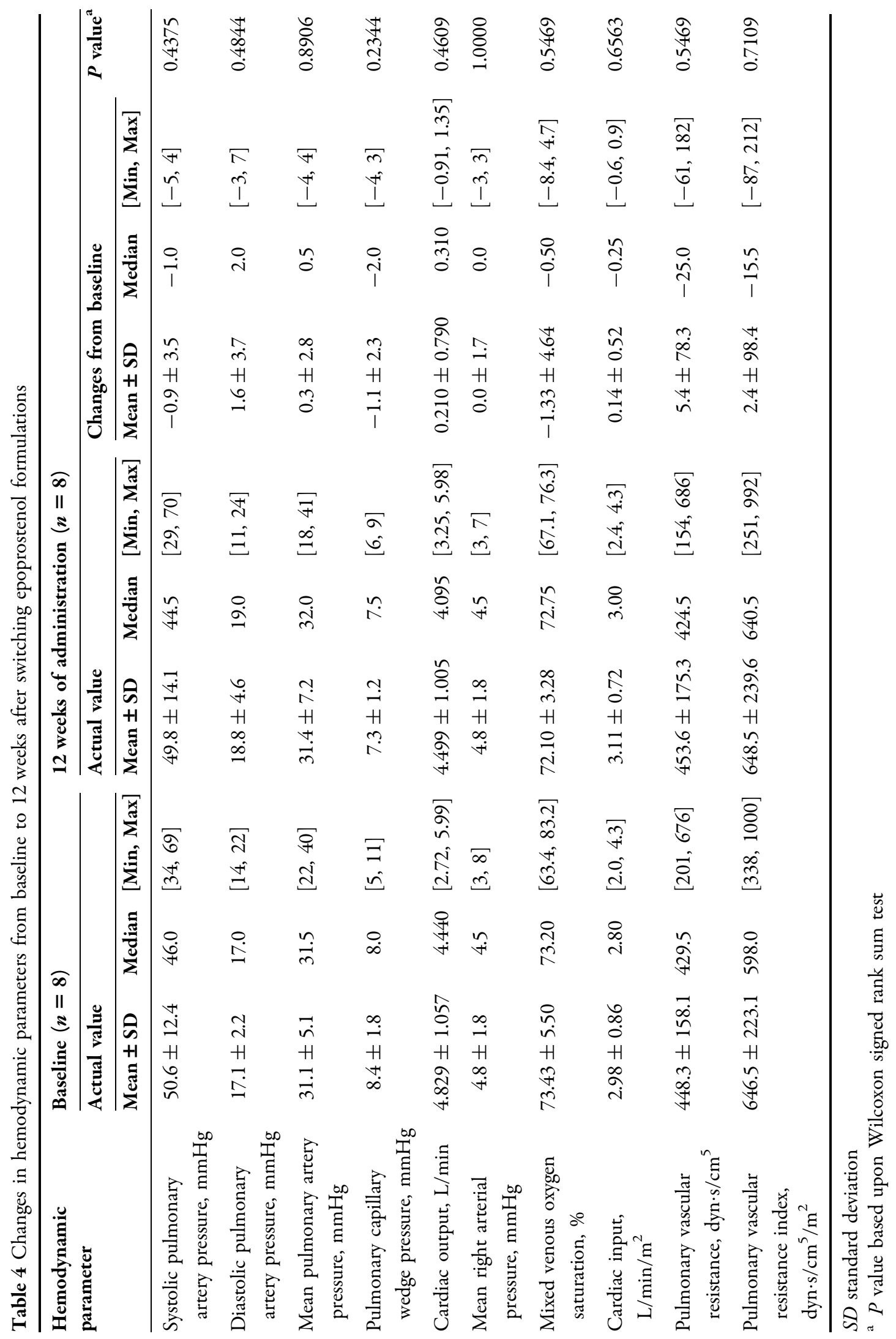

